\title{
Uma Análise Sobre a Expansão do Poder Judicial no Brasil: Construindo Sentidos sobre Democracia e Ativismo Judicial
}

\section{An Analysis on the Judicial Power Expansion in Brazil: Constructing New Meanings on Democracy and Judicial Activism}

\author{
Romano Deluque Junior
}

Universidade Federal de Mato Grosso do Sul, Programa de Pós-Graduação Stricto Sensu em Saúde e Desenvolvimento da Região Centro-Oeste; MS, Brasil. Universidade Anhanguera Uniderp, Curso de Direito. MS, Brasil.

E-mail: romanodeluque@gmail.com

\begin{abstract}
Resumo
Da descrença de um povo junto aos seus representantes eleitos ascende o protagonismo do Poder Judiciário. Nunca antes na história nacional, os olhares populares, agora dotados de uma aguçado poder de corte, se voltaram às decisões proferidas pelos Tribunais e Cortes superiores. Desse modo, decisões de questões políticas, sociais e morais de grande relevância, que outrora seriam resolvidas por instâncias políticas tradicionais como o Executivo e o Legislativo, agora são prostradas a serem apreciadas pelo Poder Judiciário. Com a fragilização das instituições politicas, judicializa-se a vida. No Brasil de nossos dias não é preciso olhar para muito além do horizonte para perceber que a relação do povo junto aos seus representantes democraticamente eleitos se encontra fragilizada, isso não é novidade. Esse fenômeno faz emergir uma atitude proativa por parte dos juízes e Tribunais brasileiros. Eis o ativismo judicial, uma ideia que se associa a uma participação mais intensa e abrangente do Poder Judiciário na concretização dos valores constitucionais e na defesa dos direitos humanos, o que não significa, em hipótese alguma, dever agir com parcialidade ou com princípios político-partidários. O presente artigo tem por intuito desenvolver um debate, na forma de uma revisão de literatura, a respeito do tema da judicialização da política e do ativismo judicial. A análise de tais fenômenos se fará à luz dos acontecimentos políticos, e jurídico-sociais que emergiram recentemente em realidade nacional. Portanto, discutir-se-á o papel do juiz proativo e seus limites de julgar, bem como as novas matizes do jogo democrático que se instauram no cenário da política brasileira.
\end{abstract}

Palavras-chave: Judicialização da Política. Ativismo Judicial. Corrupção. Democracia. Sociedade.

\begin{abstract}
From the people's disbelief towards their elected representatives, the leading role of the judiciary arises. Never before in our national history, popular views, now endowed with a sharp cutting power, have turned to the decisions handed down by our courts and higher courts. Thus, decisions of political, social and moral issues of great relevance, which in the past would have been resolved by traditional political instances such as the executive and the legislature, are now prostrate to be appreciated by the judiciary. With the weakening of political institutions, life is legalized. In Brazil nowadays, it is not necessary to look far beyond the horizon to realize that the people's relationship with their democratically elected representatives is weakened, which is not a novelty. This phenomenon gives rise to a proactive attitude on the part of Brazilian judges and courts. This is judicial activism, an idea that is associated with a more intense and comprehensive participation of the judiciary in the realization of constitutional values and in the human rights defense, which does not, under any circumstances, mean having to act with partiality or with political-political principles. supporters. This article aims to develop a debate, in the form of a literature review, on the theme of judicialization of politics and judicial activism. The analysis of such phenomena will take place in light of the political, and legal-social events that have recently emerged in our national reality. Therefore, the proactive judge's role and his or her judgment limits will be discussed, as well as the new democratic nuances game that are established in the Brazilian political scene.
\end{abstract}

Keywords: Politics Judicialization. Judicial Activism. Corruption. Democracy. Society.

\section{Introdução}

Da descrença de um povo junto aos seus representantes eleitos ascende o protagonismo do Poder Judiciário. Nunca antes na história nacional, os olhares populares, agora dotados de uma aguçado poder de corte, se voltaram às decisões proferidas pelos Tribunais e Cortes superiores. Assim, o que se deseja dizer é que, decisões de questões políticas, sociais e morais de grande relevância, que outrora seriam resolvidas por instâncias políticas tradicionais, leia-se Executivo e Legislativo, agora são prostradas a serem apreciadas pelo Poder Judiciário. Eis à judicialização, um verdadeiro desafio para um poder institucional que, até alguns anos atrás, vivia afortunadamente longe dos holofotes. Deixou-se de lado, ao menos um pouco, o futebol, e ligou-se na TV Justiça. O mesmo vale para o carnaval.

Ativismo judicial, por sua vez, não é fato, mas atitude (BARROSO; OSÓRIO, 2018), representa a escolha de um modo "específico e proativo de interpretar a Constituição" (p1). Se relaciona, sobretudo, aos atos de interpretação pessoal do julgador, quando as diretrizes não estão expressas no texto legislativo. A situação é complexa e controvertida, vem, assim, sendo debatida nos Estados Unidos desde 1803 no caso Marbury versus Madison, um verdadeiro leading case review na Suprema Corte Americana. Na ocasião se discutiu se os atos do Poder Executivo seriam passíveis de controle jurisdicional, tanto quanto à constitucionalidade quanto em relação à legalidade de seus atos (STERN, 2016; BARROSO, 
2009). Já no Brasil, são poucas as iniciativas que intentam no sentido de matizar a referida questão (TASSINARI, 2013).

A problemática aqui em pauta perpassa junto à discussão sobre até que ponto devem os fundamentos políticos incidirem nas decisões judiciais. É claro que toda decisão judicial é, de alguma forma, amparada sob uma realidade política, na qual o magistrado se insere (GADAMER, 1997), porém o que se visa discutir é a conduta ética diante de um eventual partidarismo no processo de tomada de decisões por parte do magistrado. Dito isso, propõe-se a discutir aqui os papéis da ética e da moralidade no que tange ao uso de motivações políticas na tomada de decisões judiciais.

Com a fragilização das instituições politicas, judicializase a vida (BARROSO; OSÓRIO, 2018; BARROSO, 2009). No Brasil de nossos dias não é preciso olhar para muito além do horizonte para perceber que a relação do povo junto aos seus representantes democraticamente eleitos se encontra fragilizada, isso não é novidade. Também não é, com o perdão pelo juízo de valor, injustificada. Escândalos de corrupção como o Mensalão e os expostos pela Operação Lava Jato fizeram, de fato, o brasileiro perceber que há algo de muito errado em uma sociedade na qual os impostos arrecadados são "aleatoriamente" divididos, licitações fraudadas, e a corrupção, endêmica. Passados os últimos eventos e manifestações sociais, hoje no Brasil já se sabe e concebe, que a ordem política deve visar o bem do povo, e o político eleito, tal como instrumento dessa ordem, existe a serviço desse povo (SILVA, 2014; SANTOS, 2013). Iniciaram-se as cobranças, a conta sempre chega.

O intuito do presente artigo é o de desenrolar um debate a respeito do tema da judicialização da política e do ativismo judicial. A análise de tais fenômenos jurídicos se fará à luz dos acontecimentos políticos, e jurídico-sociais que emergiram recentemente em realidade nacional. Portanto, discutir-se-á o papel do juiz proativo e seus limites de julgar, bem como as novas matizes do jogo democrático, que se instauram no cenário da política brasileira.

\section{Desenvolvimento}

\subsection{Um despertar mais que tardio}

Quando se traz um prelúdio sobre a história de uma nação, frequentemente, se remete a um passado mais ou menos distante da realidade atual, não se concebe, na maioria das vezes, que a história pode estar sendo escrita no aqui e no agora. História é o que está nos livros, assim se pensa. Um ledo engano.

Não é só por 20 centavos! Bradava a altiva multidão na Avenida Paulista em meados de Junho de 2013, em manifestação que tomou forma, com raríssimas exceções, em todas as capitais do país. Conforme hoje se recorda, este foi um evento de proporções faraônicas, cuja energia e alcance não se aflorava desde o impeachment do ex-presidente Fernando Collor. Era chegado o fim da era da tolerância à corrupção e à indiferença dos políticos em relação à seus governados. Um rechaço ríspido contra a surdez de um Estado.

O copo da paciência popular transbordou. Os protestos de rua se alastraram pelo país como um incêndio que fazia crepitar o chão, transformando em cinzas a empáfia do proselitismo oficial, e em fumaça o lero-lero demagógico das oposições convencionais. A pancada atingiu o cerne do discurso do governo federam, que balançou na hora, de forma apalermada, sem saber como reagir, mas demorou para ir a nocaute. Passados três anos, em 2016, após o crivo das eleições, a presidente veio abaixo (BUCCI, 2016, p.11).

Estava chegando ao fim o período de Governo do Partido dos Trabalhadores, que ao final de exatos treze anos e cinco meses de Governo, caía em substancial descrédito perante a sociedade. Frise-se, porém, que apesar de se ouvirem gritos tais, como: "nossa bandeira jamais será vermelha", em clara referência às cores do partido governista, a origem do sentimento nacional era muito mais profunda, remetendo à mudança de uma, se assim se pode chamar, consciência coletiva, em forma de um grande basta à classe política dominante, e aos políticos do establishment vigente. Mais do que isso, era um grito contra a cegueira governamental, ao cinismo político, à cultura do gift gift ou do toma lá da cá. $\mathrm{O}$ brasileiro, enfim, despertou.

As manifestações de 2013 emergiram, a princípio, contra o reajuste no transporte coletivo e a truculência do aparato repressivo do Estado de São Paulo (SANTOS, 2013) e, a partir das redes sociais, eficiente ferramenta de mobilização coletiva, os manifestantes foram cada vez mais convocados para reclamar essas, e outras demandas. Como manifestação social, o coro de 2013 uniu, de maneira nunca antes vista, a esquerda e a direita, o Norte e o Sul, o rico e o pobre. Um evento histórico legitimado pelo próprio povo, um retumbante exaltar da democracia. Nas palavras de Santos (2013, p.17):

Tratou-se pois, de "uma coalizão a congregar militantes do Movimento pelo Passe Livre (MPL); jovens e não tão jovens radicais de esquerda, filiados a partidos como PSOL e PSTU; ativistas de causas sociais as mais diversas (índios, LGBT, negros etc.); segmentos das classes alta, média alta e da nova classe média; órfãos de alternativas partidárias consistentes à direita do espectro político; anarquistas e ativistas conectados a movimentos internacionais de protesto; além de neonazistas e fascistas assumidos, adeptos da violência e da intolerância como meios legítimos de manifestação e expressão de preferências e valores.

\section{O autor complementa:}

Desprovidos de uma reivindicação específica, como nos episódios das 'Diretas já' ou do impeachment do presidente Fernando Collor, encontravam-se todos ligados numa mesma emoção: participar, protestar, se expressar, eventualmente de forma violenta, gritar palavras de ordem, portar cartazes, vestir máscaras, enfim, sentir a euforia de fazer parte de um movimento de massa de proporções inéditas (SANTOS, 2013, p.18).

Os aportes a respeito desse período histórico do país se fazem plenamente relevantes à discussão, pois demonstram 
importante mudança dos conceitos de "política" e de "político" a partir do discurso e das lentes do brasileiro (MEDEIROS; SILVEIRA, 2017). Há de se dizer que a questão é tanto quanto mais complexa do que enxergam os olhos, obviamente, o núcleo motivacional dos protestos foi em muito suplantado, e novas demandas foram assim, levantadas. A questão passava a ser, então, hermenêutica, interpretativa, dever-se-ia se fazer entender os sentimentos e significados das ruas. Nesse interim, partidos políticos tentaram tirar proveito, foram expulsos. Sindicatos ousaram demandar, tiveram seus cartazes rasgados e placas quebradas (SANTOS, 2013).

Da inépcia interpretativa da governança, bem como dos partidos políticos de oposição, houve então um estrago. $\mathrm{Na}$ falha de tradução dos sentimentos difusos da população, denegriu-se a classe política quase que como um todo, os políticos passariam a ser vistos, desde então, como uma nobreza corrupta, o problema da nação e, sua articulação partidária seria, em regra a partir de então, algo semelhante a uma associação para o crime. A salvação, então, repousaria na exceção, nos ombros de outsiders, nos políticos antiestablishment, na nova ordem, e isso é, para dizer o mínimo, digno de ressalvas, pois pode proporcionar a ascensão de políticos demagogos dotados de enorme poder de persuasão e de desprezo absoluto pelas regras do jogo democrático e pelo Estado de Direito (LEVITSKY; ZIBLATT, 2018). É preciso ter em mente que o retrocesso democrático hoje começa nas ruas e a via eleitoral para o colapso é perigosamente enganosa.

\subsection{Do Mensalão à Lava Jato}

O presente tópico se faz necessário nesta discussão, pois evidencia uma trajetória político-social que, iniciada no ano de 2005, acabou por contribuir para a construção de uma nova relação do eleitor junto à classe política vigente na atual sociedade brasileira. Segundo Michener e Pereira (2016), o escândalo do Mensalão foi o mais notável caso de corrupção envolvendo políticos no Brasil, de modo que mais de 28 indivíduos foram condenados por estarem relacionados com um esquema legislativo de compra de votos de parlamentares. Juridicamente conhecida como Ação Penal $\mathrm{n}^{\mathrm{o}} 470$, essa chocou tanto os brasileiros quanto a comunidade internacional por escancarar um enorme esquema de lavagem de dinheiro que envolveu membros do mais alto escalão do Governo Federal, além de executivos de grandes empresas e funcionários públicos de alta patente (MICHNER; PEREIRA, 2016; MIGUEL; COUTINHO, 2007).

$\mathrm{O}$ caso veio à tona quando o então Deputado Federal Roberto Jeferson, ex-filiado ao partido governista da época, decidiu denunciar no mais alto tom, fazendo uso de sua reconhecida capacidade retórica, um esquema de corrupção no qual ele mesmo se encontrava envolvido (MICHNER; PEREIRA, 2016; SILVA, 2014). O mensalão afetou, de maneira profunda, o primeiro mandato do então Presidente da República Luís Inácio Lula da Silva, primeiro governante de esquerda a assumir o país após o retorno da democracia (SILVA, 2014), e trouxe consigo um cenário nunca antes visto de polarizações políticas e de quebra de confiança do eleitor para com seus eleitos. Tratou-se de um claro divisor de águas no campo da política institucional brasileira que se encerrou com um feito que em poucas democracias pôde ser observado: o exercício de adequado procedimento judicial que havia sido empregado, independentemente das dinâmicas e das influências político-partidárias (MICHNER; PEREIRA, 2016).

A operação Lava Jato, no entanto, encontra-se muito mais presente no imaginário social do brasileiro, e afeta, ainda nos dias atuais, o cotidiano dos envolvidos direta ou indiretamente junto ao caso, bem como àqueles que se propõem de alguma forma, pensar o contexto político brasileiro. A $1^{\mathrm{a}}$ fase da operação é recente, e se desencadeou em 17 de março de 2014, quando então um esquema de desvio e lavagem de dinheiro foi descoberto funcionando em um posto de gasolina anexo a uma lavanderia (RIBEIRO; MARTINS, 2016), e envolveu a companhia estatal de petróleo - Petrobras, grandes empreiteiras e, uma vez mais, partidos, indicados, e dirigentes políticos (MEDEIROS; SILVEIRA, 2017).

Para se ter uma ideia do alcance da operação, bem como da sua contundência, basta citar alguns dados a respeito da cobertura midiática que foi feita sobre esse. Em estudo publicado em Julho de 2017, Medeiros e Silveira (2017) afirmam que do início da operação, até a publicação do respectivo estudo, dois dos grandes instrumentos de alcance de mídia nacionais, cite-se, a Folha de São Paulo e a Revista Veja, não publicaram uma só edição sem que alguma reportagem se relacionasse, de alguma forma, com a Lava Jato.

Os temas tratados pela mídia variam, indo do envolvimento de doleiros em lavagem de dinheiro, passando por diretores de estatais repassando propina aos políticos, e chegando até uma complexa sistematização do sistema de propinas e repasses feitos por grandes empreiteiras (MEDEIROS; SILVEIRA, 2017; MELO, 2016). Até o final de 2017 foram mais de 155 mandados de prisão preventivas, outros 155 expedidos para prisões temporárias, 183 acordos de colaboração premiada e mais de $\mathrm{R} \$ 40,3$ bilhões como forma de ressarcimento pedidos pelo Ministério Público Federal (MPF-PR, 2019). Os números impressionam.

Cabe, nesse ponto desta discussão, o seguinte questionamento: de que forma esses e outros escândalos de corrupção influenciam o imaginário popular e, quais as consequências desta possível influência? Parte desta resposta é trazida por Chaia (2015), quando afirma que embora pessoas sejam envolvidas, reputações sejam questionadas e carreiras políticas destruídas, o mais relevante repousa sob a perda de confiança e de legitimidade em relação ao papel de determinadas instituições e à generalização. Conforma aduz a autora:

A mídia em alguns escândalos exagera em suas observações 
e avaliações, chegando a generalizar certas atitudes, como se toda a categoria dos políticos agisse de maneira comum. $\mathrm{O}$ político, em alguns momentos, é avaliado negativamente e torna-se sinônimo de corrupç̣ão (CHAIA, 2001 p.6-7).

No desenrolar, e a partir do desfecho de tais eventos, ascendeu-se uma desconfiança em nível nacional com relação às instituições $\mathrm{e}$ às pessoas envolvidas nos respectivos contextos. Perdeu-se, portanto, a confiança em tantos quanto possíveis integrantes da classe política e em seus respectivos partidos, criando-se, assim, a partir de um sentimento de generalização por parte da opinião pública, uma verdadeira ojeriza em relação aos políticos do establishment vigente e aos ligados, de alguma forma, ao que hoje se considera como sendo a velha ordem política.

Nesse mesmo sentido, a cobertura da mídia exerce papel decisivo (CIOCCARI, 2015; McCOMBS; SHAW, 2000), correndo o risco de, às vezes, distanciar-se de uma pretendida neutralidade para enquadrar um tom mais ou menos acusatório, cuja capacidade de talhar a própria feição à opinião popular é latente (CIOCCARI, 2015). Uma forte tendência à generalização é perceptível em tais contextos, sentidos são atribuídos em forma de opiniões dirigidas para toda uma classe, que pode ser política, institucional, ou partidária.

Passa-se, então, a uma busca de figuras idealizadas, que representem um ideal moralmente aceito e, que acenem para uma ética contramajoritária, de oposição aos malfeitos institucionais e ao crime. Assim, aquele que processa ou manda prender acena com o incorruptível, e transcende, no imaginário coletivo, o liame do bem e do mal. Eis que as luzes se voltam para o Judiciário, reduto ainda, de boa moral e de integridade institucional.

\subsection{O Fenômeno da Judicialização}

Judicialização e Ativismo Judicial são fenômenos distintos e não se confundem (BARROSO; OSÓRIO, 2018; TEIXEIRA, 2012; BARROSO, 2009). Esse último se refere à maneira proativa de interpretar a norma jurídica, ou seja, de talhar em determinada decisão judicial entendimentos estritamente particulares, que vão além da letra crua da lei. Já o sintagma judicialização traz consigo um conteúdo distinto deste último, e embora seja utilizado erroneamente como um sinônimo, se refere à transferência aos Tribunais e juizes, a responsabilidade de decidir sobre questões políticosociais relevantes, que seriam, tradicionalmente decididos por instâncias políticas eleitas ou mesmo administrativas.

Percebe-se, no Brasil, principalmente nos últimos dez anos, um movimento de ascensão no que tange aos reflexos de decisões judiciais junto à sociedade brasileira. Tais decisões se tornam públicas quase que em tempo real, e lapidam constantemente a imagem do judiciário no imaginário social da população, e nesse contexto, cabe destacar a evidência que o Superior Tribunal Federal (STF) assume ao decidir tais questões. A suprema corte brasileira nunca foi tão cortejada e instigada a decidir sobre os mais diversos temas relacionados com a Constituição Federal. A situação é potencializada pelo fato de se possuir no país uma constitucionalização abrangente (BARROSO; OSÓRIO, 2018), que traz para si matérias e responsabilidades que, em tantos outros países democráticos, são decididas pelo Legislativo e regulamentadas por leis infraconstitucionais em forma de legislação ordinária.

O potencial de abrangência dessas decisões é bastante amplo e essas são, em sua maioria, relacionadas à dignidade da pessoa humana. Porém, mais recentemente, essas têm sido ligadas ao combate à corrupção. Assim, decide-se sobre cotas raciais, pesquisas com células tronco (BARROSO, 2011), internação compulsória em caso de dependência às drogas (BARTOLOMEI; REZENDE, 2017), entre tantos outros temas. A questão é complexa e pede ponderação, de modo que o que pode estar em análise é um caso concreto ou uma situação hipotética, um direito em tese, como se vislumbra nos diversos instrumentos de controle concentrado de constitucionalidade como a ação direta de inconstitucionalidade (ADI), ou a ação declaratória de constitucionalidade (ADC). De toda sorte, tanto uma quanto outra exercerão efeitos diretos na vida das pessoas, abrindo precedentes, gerando jurisprudências, e direcionando a criação de normas jurídicas (BARROSO, 2009).

É com a fragilização das instituições politicas que a tendência de judicialização a vida é amplificada (BARROSO; OSÓRIO, 2018), e é nesse momento de ascensão do Poder Judiciário que reside um importante ponto que carece de reflexão. Essa sugere um questionamento sobre qual seria então o mais adequado ponto de equilíbrio, e quais os limites para a atuação de cortes superioras e de Tribunais regionais frente às problemáticas que lhes são dispostas. Parece, pois, uma questão complexa, visto que acertar a correta calibragem em um número imensurável de questões que envolvem as mais diversas relações sociais seja essas cíveis, ambientais, políticas, religiosas ou penais, beira o impossível e flerta com o improvável, pois o magistrado é, sobretudo, humano.

Para proceder em uma discussão conceitual, cabe dizer que o fenômeno da judicialização é considerado gênero, do qual decorrem várias espécies como a judicialização da vida, do direito, da política, do meio ambiente, etc (LEAL \& ALVES, 2014). Há, porém, uma inadequada indistinção acadêmica acerca do tema da judicialização, em que esse é utilizado de maneira genérica, sendo distinguido, na maior parte das vezes, nas doutrinas sobre Direito e Constitucional e em artigos científicos específicos (BARBOSA; KOSICKI, 2012).

Em uma reflexão sobre democracia, judicialização e ativismo judicial, tal como se propõe este estudo, convém construir uma discussão sobre os aspectos da judicialização da política no país. Esta é comumente apresentada como sinônimo de uma ideia genérica de ativismo judicial e, embora se confundam, é preciso proceder a uma evolução conceitual a respeito do tema, pois a partir dessa se poderá criar uma discussão de melhor qualidade a respeito do mesmo. 
É na tentativa de garantir à sociedade seus direitos fundamentais, constantes na Constituição Federal que a política se judicializa (BARBOSA; KOSICKI, 2012). O fenômeno da judicialização da política pode ser explicado em parte em função da existência de um novo modelo de aplicação dos direitos fundamentais, que supera o modelo anterior pautado na estrita separação de poderes (VERBICARO, 2008), tal inovação proporciona uma maior interação entre os poderes constitucionais, o que inclui uma maior participação judiciária em assuntos propensos ao Legislativo e ao Executivo.

A partir desse modelo, a atuação dos três pilares institucionais poderia ser observada a partir de um ponto de vista que contemple um funcionamento dinâmico entre esses, algo próximo a um único organismo social dotado de três grandes matrizes de força. Quando uma dessas matrizes não vai bem, a outra atuaria, diga-se, de maneira autônoma, para manter a grande máquina em funcionamento, balanceando seu curso e corrigindo as falhas.

No entanto, o pragmatismo que emerge na realidade brasileira leva a crer que o descrédito que foi atribuído à classe política nos últimos anos parece exercer papel vital na transferência de responsabilidades na direção do Judiciário como aqui se discute. Dessa forma, é possível afirmar, conforme expõe m Tate e Vallinder (1995), que a inefetividade das instituições políticas majoritárias em resolver questões consideradas problemáticas do ponto de vista eleitoral acaba por transpor a responsabilidade para o Judiciário.

No processo de descredibilizacão de um órgão ou instituição pública existe, sobretudo, uma questão de imagem, que não se pode deixar de levar em consideração que diante de um legítimo Estado Democrático de Direito, a opinião pública é relevante e possui peso substancial diante do processo de tomada de decisões por parte dos integrantes dos nossos órgãos institucionais, pertençam esses ao Legislativo, Executivo, ou Judiciário.

Quando determinado público, ou líderes de grupos de interesse passam a perceber que determinadas instituições majoritárias estão a trabalhar por interesses próprios e, por vezes, escusos, a sociedade acaba por endossar, ainda que tacitamente, que outras instituições atuem em defesa daquilo que parece ser, naquele momento, seus interesses (FEREJOHN; PASQUALINO, 2003). Nesse sentido, há de se ressaltar que nada influencia tanto a imagem de um poder institucional perante o público quanto a cobertura que é desempenhada pela mídia, esse processo acaba, às vezes, por traduzir aquilo que ocorre dentro dos Tribunais e das sessões legislativas com um significado que lhe é próprio e, característico ao perfil de cada um dos meios de comunicação (McCOMMBS; SHAW, 2000). Emergem, então, potenciais parcialidades em coberturas jornalísticas, que contribuem para a construção de uma imagem que, por vezes, foge ao verossímil e ao imparcial.

Basta lembrar que em meados de 2012, com o início do julgamento da primeira fase do Mensalão, nunca tinha se falado, lido, ou observado tanto o que fazia o Supremo Tribunal Federal (MELLO, 2018; MELLO, 2015). A intensidade da cobertura midiática diante do evento, tanto pela TV Justiça, como através de veículos de comunicação privados, fez com que praticamente toda uma nação tomasse conhecimento dos intensos debates travados na corte. Passouse assim uma imagem de que um feito inédito ali ocorria, uma superação da cultura da impunidade que se entendia intocável e predominante naquela época. Marcou um ponto de mudança para a Suprema Corte Brasileira, tanto que:

O relator do caso, Ministro Joaquim Barbosa, que teve uma atuação extremamente aguerrida pelas condenações, foi homenageado por diversas instituições da sociedade civil. O Supremo mudara de posição no imaginário popular: de um órgão distanciado e de difícil acesso, para um Tribunal que encarnava os anseios de justiça dos brasileiros (MELLO, 2018 p.12)

Um outro ponto merece ainda ser destacado no que tange à alteração da imagem do STF perante a opinião pública. Em 2002 resolveu-se criar então a TV Justiça, um canal de televisão gratuito destinado ao Supremo Tribunal Federal, e por meio desse as sessões passaram a ser transmitidas ao vivo. $\mathrm{O}$ que antes habitava apenas em uma discreta penumbra institucional, viria a habitar os lares e os imaginários brasileiros (MELLO, 2018).

Não parece haver dúvida de que essa projeção midiática alterou o funcionamento da corte, ministros passaram a ser vistos como figuras públicas, e a exercer papel de destaque diante dos noticiários e da opinião pública. Houve aí, uma inegável mudança comportamental, humanizaram-se as sessões de julgamento, ministros passaram a utilizar, às vezes, uma linguagem mais popular e tangível ao público em geral, rompeu-se dessa maneira, um ciclo histórico de indiferença, complacência e impunidade (MELLO, 2018). Construiu-se um verdadeiro capital político dentro do STF.

Para se entender melhor o fenômeno da judicialização na política no Brasil, pode-se utilizar como ponto de partida a competência originária do STF para julgar ilícitos, possivelmente, cometidos por políticos investigados. Isso por si só cria uma espécie de intervenção do STF nos demais poderes, apenas para citar um exemplo, vislumbra-se que a Suprema Corte, ao condenar um Deputado Federal ou um Senador, acaba por mobilizar todo um jogo de interesses de modo a reequilibrar a dinâmica das casas legislativas, e esse fenômeno é autônomo, não pode ser controlado. Assim, é possível observar que até mesmo a mais simples "[...] condução ordinária das investigações e ações penais pelo Supremo passa a produzir impacto imediato no equilíbrio de forças no parlamento e nos rumos da vida política nacional" (BARROSO; OSÓRIO, 2018 p.4).

Esse fenômeno é potencializado pelos escândalos de corrupção que emergem quase que de maneira rotineira no país, de modo que a abertura de inquéritos, o recebimento 
de denúncias, as conduções coercitivas, e a decretação de medidas cautelares como a prisão e o afastamento do mandato projetam a realidade política para dentro dos limites do Supremo Tribunal Federal, causando, pois, uma demasiada exposição do Tribunal à opinião pública e, ao mesmo tempo, aumentando os riscos de decisões indevidamente politizadas, e de seletividade dos julgamentos e de intervenção desmedida no jogo politico (BARROSO; OSÓRIO, 2018). E a esse fenômeno de politizacão das decisões judiciais se dá o nome de ativismo judicial, objeto de estudo que precisa ser ponderado e estudado, como se verá mais adiante.

De toda sorte, parece que a partir do esvaziamento da credibilidade e da legitimidade dos representantes eleitos, a esperança, e por conseguinte, a cobrança por parte da opinião pública passa a se dirigir a um último reduto de boa moral existente nos Poderes institucionais, de modo que nunca antes o destino político do país esteve tão dependente de desfechos de processos criminais e, portanto, sujeitos às decisões do Supremo Tribunal Federal.

\subsection{O Ativismo Judicial}

O contato com a ideia de ativismo judicial é bastante comum para os que estão, de alguma maneira, inseridos dentro de algum contexto relacionado ao estudo do Direito. Em cursos de graduação, por exemplo, a temática é bastante citada, em geral se relacionando ao exercício arbitrário de decisão judicial promovido por um determinado magistrado, ou seja, fala-se de ativismo judicial querendo se referir ao decidir "ao meu ver" e "ao meu sentir". Tal definição é demasiado simples e carece de aprofundamento.

Segundo Barroso (2009), o ativismo judicial se relaciona a uma escolha, uma atitude proativa do magistrado de interpretar a Constituição, de modo a expandir o seu sentido e alcance, "normalmente esse se instala em situações de retração do Poder Legislativo, de um certo descolamento entre a classe política e a sociedade civil, impedindo que as demandas sociais sejam atendidas de maneira efetiva" (p.6). É uma ideia que se associa a uma participação mais intensa e abrangente do Poder Judiciário na concretização dos valores constitucionais e na defesa dos direitos humanos, o que não significa, em hipótese alguma, dever agir com parcialidade ou com princípios político-partidários.

Tal como a judicialização, o ativismo judicial se relaciona à deslegitimação da classe política, quando essa se apresenta como incapaz de realizar os valores pré-determinados pela sociedade em seu respectivo cotidiano. Nesse contexto, cabe a ressalva de que a corrupção, o uso da política para atender interesses partidários, "bem como a burocratização estatal, são três componentes sociológicos que corroboram para fortalecer o mito do juiz Hércules no subconsciente coletivo e culminar na crescente judicialização das relações sociais" (TEIXEIRA, 2012, p.2).

No Brasil, o tema ganhou expressão com a promulgação da Constituição Federal de 1988. Essa que, cabe ressaltar, delega um conjunto de prerrogativas aos órgãos judiciários e, por conseguinte, aos magistrados, isso por sua vez impulsiona a uma atuação mais presente e proativa diante das problemáticas que lhes são cotidianamente remetidas (BARROSO, 2018). Nesse mesmo sentido, a judicialização das questões politicas e sociais, bem como as diversas modalidades de acesso para se discutir o controle de constitucionalidade se apresentam como fenômenos potencializadores de um decidir mais proativo por parte dos magistrados, em especial pelo STF. Nesse sentido, Teixeira (2012, p.40) contribui com as seguintes palavras:

Um debate (sobre a constitucionalidade das leis), que antes de 1965 ficava primordialmente concentrado no meio político, hoje concentra-se cada vez mais nas instâncias judiciais ordinárias, que estão em condições de exercer o controle difuso, mas também concentra-se, derradeiramente, naquilo que é decidido no juízo abstrato do Supremo Tribunal Federal.

Quanto à judicialização das relações sociais, essa se refere a uma perda dos sentimentos de comunidade, e de identidade (TEIXEIRA, 2012). Acaba, assim, por flertar com um estado constante de desconfiança na relação com o outro, que culmina na perda de uma sensibilidade que venha a apontar um norte de valores éticos e morais. Desse modo, judicializase praticamente tudo, inclusive a vida (BARROSO, 2009), ou seja, posterga-se ao terceiro imparcial, o pleno direito de decidir.

O fenômeno da judicialização das relações sociais já bastaria, por si só, para proporcionar um clima adequado para posturas ativistas por parte dos magistrados de um modo latu, porém, a judicialização da política adquire delineamentos bastante concretos nesta realidade nacional. Essa, por sua vez, age com especificidade e representa a expansão do poder dos juízes e a transferência do poder de criação normativa, característico do Legislativo, para o Judiciário; e a criação de métodos e técnicas decisórias fora daquilo que habitualmente tem sido utilizado (TEIXEIRA, 2012). A partir dessa expansão do poder de decidir, e da criação de métodos hermenêuticos que lhes sejam próprios, é que os limites entre o Direito e a Política começam a ser questionados.

O oposto de ativismo é a autocontenção judicial, e significa justamente o agir com uma postura mais passiva por parte dos magistrados, de modo a se analisar os fatos com um olhar menos sensível aos anseios da população e da opinião pública, ou seja, agir com uma conduta que vise a menor interferência possível nos outros poderes institucionais. $\mathrm{O}$ binômio "ativismo-autocontenção judicial está presente na maior parte dos países que adotam o modelo de supremas cortes ou tribunais constitucionais"(BARROSO, 2009, p.9), e costuma funcionar com um movimento pendular: quanto maior o grau de prestígio de um poder institucional perante a opinião pública, maior é a autocontenção judicial e menos intensa é a postura de ativismo por parte do judiciário, e vice versa (TATE; VALLINDER, 1995).

No Brasil, pode-se afirmar, com alguma segurança, que o Congresso Nacional não tem se apresentado, ao menos 
de acordo com a opinião pública, tal como um reduto de ética e de moralidade (ENGELMANN, 2017; CIOCCARI, 2015). É possível, inclusive, dizer que, nos últimos anos, "uma persistente crise de representatividade, legitimidade e funcionalidade no âmbito do Legislativo tem alimentado a expansão do Judiciário nessa direção" (BARROSO, 2009 p. 9). Essa falta de credibilidade acaba por gerar omissões no que tange aos anseios da população e, nesse sentido, as decisões do judiciário de questões políticas que foram judicializadas a priori, intentam sanar essas mesmas omissões, mesmo que para isso, às vezes, tenham que inovar na ordem jurídica. Eis o ativismo judicial presente e atuante neste contexto político diário.

Esse fenômeno tem uma face positiva, pois demonstra que '〈o Judiciário está atendendo a demandas da sociedade que não puderam ser satisfeitas pelo parlamento, em temas como greve no serviço público, eliminação do nepotismo ou regras eleitorais" (BARROSO, 2009, p.9). A face negativa repousa no ponto em que o fenômeno escancara a atual da situação política e social brasileira, em um contexto em que as desigualdades sociais só aumentam, a adiada reforma política se apresenta como uma necessidade dramática do país, para fomentar autenticidade partidária, estimular vocações e reaproximar a classe política da sociedade civil (BARROSO, 2009).

\subsection{Discussão}

Nos apontamentos anteriores foi feito um esforço no sentido de esclarecer a respeito do modo adequado de se entender o fenômeno da judicialização e do ativismo judicial. Tal discussão não possui o intuito de se fazer definitiva, tampouco pode pretender esgotar o assunto ou delimitar o seu alcance. Trata-se apenas de uma reflexão, sobretudo, conceitual. Também foram feitos alguns breves aportes que tentaram descrever algumas das últimas transformações sociais e eventos políticos que marcaram o país de modo indelével.

Tais aportes trouxeram à baila as manifestações populares de 2013, bem como os dois casos de corrupção que de modo mais marcante se evidenciaram na mídia brasileira e, por consequência, marcaram de forma permanente o imaginário coletivo: o Mensalão e Operação Lava Jato. A contextualização se faz necessária, pois tais eventos vieram a talhar novas opiniões e entendimentos sobre a realidade política e jurídica nacional. O debate conceitual, que aqui é proposto, está inserido em um determinado contexto político e social, e esse, diga-se de passagem, tem adquirido contornos e características únicas com o passar de todas essas transformações dos últimos anos.

Quando em um contexto político pautado na democracia, no qual se insere o país, a máxima a ser seguida é a vontade popular. A legitimidade é alcançada a partir do mandato, e esse emerge a partir do voto popular, direto, indisponível e inegociável. Democracia essa, que por sua vez constrói a partir de um modelo de ideal elevado, para cujo funcionamento se reclama do homem a virtude (FERREIRA FILHO, 2001). E mais, tem como pressuposto que o povo escolha os seus próprios representantes, e esse ato de escolher, frise-se, não se pauta em outro atributo senão as qualidades do candidato, bem como seu aceno à virtude e à honestidade.

O mandato erigido pelo voto traz consigo o poder de representação e, imprime, ainda, uma crença de legitimidade no subjetivo popular para com seus representantes eleitos. Como poderia então, um órgão não eleito democraticamente como o STF, estar legitimado a invalidar decisões que foram feitas por aqueles que exercem mandato popular?

A resposta a esse questionamento muito tem a ver com o constitucionalismo sob o qual as bases da democracia brasileira se assenta. E, nesse sentido, os sintagmas Estado Constitucional e Estado Democrático não se confundem, mas se complementam, ou conforme as palavras de Barroso (2009, p.11):

O Estado constitucional democrático, como o nome sugere, é produto de duas idéias que se acoplaram, mas não se confundem. Constitucionalismo significa poder limitado e respeito aos direitos fundamentais. O Estado de direito como expressão da razão. Já democracia significa soberania popular, governo do povo.

É nessa intersecção, entre vontade popular e obediência à Constituição, que podem emergir conflitos e tensões, típicas de um Estado Constitucional Democrático. E justamente para que a democracia não se reduza a uma autocracia ditada pela maioria, é que a constituição federal deve se fazer plena e eficaz. Ela descreve as regras do jogo democrático, garante uma participação politica ampla e a alternância de poder. Eis que a questão da legitimidade do Judiciário começa a se elucidar. Ora! Se além de regular as regras da democracia vigente, uma Constituição tem ainda a nobre função de "proteger valores e direitos fundamentais, mesmo que contra a vontade circunstancial de quem tem mais votos" (BARROSO, 2009, p.12), e o intérprete da Constituição é o STF, nada seria mais justo de que a legitimação do órgão para funcionar como um instrumento de ponderação diante de decisões autocráticas e constitucionalmente questionáveis.

Desse modo, cabe afirmar que a jurisdição constitucional, mesmo que não seja realizada por representantes eleitos é, antes uma garantia do que um risco para a democracia. Há, porém, um limite a ser postulado (SHAPIRO, 1994). É fato de que a Constituição Federal atribui poderes e responsabilidade que são inerentes ao Judiciário, no entanto, essa mesma CF dita também as regras do jogo democrático e, estabelece as especificidades e competências de cada um dos poderes institucionais. Por evidente, o ato de interpretar a Constituição não pode suprimir a política, o governo da maioria, tampouco o papel do Legislativo (BARROSO; OSÓRIO, 2018; DWORKIN, 2011; BARROSO, 2009; TATE; VALLINDER, 1995).

Uma vez observados os valores dispostos pela Constituição, 
é papel da lei, votada pelo Legislativo e sancionada pelo Executivo, se fazer valer como máxima a ser cumprida dentro de uma sociedade democrática. A intervenção do Judiciário sob leis e decretos presidenciais deve vir imbuída de leveza e, ainda, obedecer uma gramática mínima no que tange a impor as suas próprias escolhas e preferências (DWORKIN, 2011). Assim, tais intervenções, mesmo que feitas de maneira ativista, somente encontrariam legitimidade se forem racionalmente fundamentadas com base nos princípios constitucionais e, emergentes em função da defesa destes. Devem se apresentar, sobretudo, como um ponto fora curva, uma exceção..

Estabelecidos tais critérios, faz-se mais fácil vislumbrar de que forma a postura ativista de um magistrado pode ser adequada e trazer resultados benéficos a uma determinada realidade social. Todavia, essa é uma temática que se relaciona ao conceito de moral humana, em que o embate entre Direito versus justiça se evidencia. Dworkin (2011) percebe o ramo do Direito tal como uma modalidade de moral política, ou seja passível de reflexões epistemológicas e filosóficas em espectro amplo. Para o autor, é finado o tempo em que o Direito e a moral eram vistos como dois sistemas em separado e distintos. Essa teoria caiu para dar espaço a um só mecanismo, no qual a moral pessoal emergiria a partir da ética, e a moral política a partir da moral pessoal. Logo, sem sólidos atributos éticos, a sociedade sobressairia o encargo de lidar com uma ordem política aquém do aceitável e, distante assim, de preceitos como probidade e lealdade.

No contexto do ativismo judicial se poderia facilmente hipotetizar situações nas quais os juízes se deparariam com leis injustas e inadequadas, e que essas, apesar de não ferirem preceitos constitucionais expressos, estariam sujeitas sim a uma análise mais individualizada e precisa por parte do Judiciário. Tal postura seria, segundo Dworkin (2011), a plena manifestação da moral política através do Direito, pois neste instante o magistrado agiria em nome de um sujeito coletivo, cujos valores morais the impelem a se importar com o outro.

\section{Conclusão}

O Judiciário é, pois, o guardião da Constituição e das normas infra-constitucionais, e portanto, deve fazê-las valer mesmo que para isso tenha que proferir decisões impopulares e contramajoritárias. Trata-se de uma atitude em favor da democracia e pautada em uma moral política que, supõe-se, se baseia em princípios éticos preocupados com o comum proveito. Agir em favor da dignidade da pessoa humana e em defessa dos princípios constitucionais, às vezes, significa contrariar a opinião pública e a vontade da maioria. É uma questão que faz transcender a ciência do Direito do mero positivismo e o faz flertar com uma verdadeira ética aristotélica.

O magistrado é, antes de mais nada, um ser humano, mas é também um hermeneuta, um intérprete das leis e dos textos normativos. Deve-se apegar a esses, defendê-los, mas sobretudo, compreendê-los em seu respectivo tempo e espaço, ou seja, diante de seu contexto político e social. Passaria assim a uma condição de hermeneuta social, aquele que compreende a lei em seu sentido histórico e a aplica no melhor sentido pragmático. Logo, aplicar a lei, a partir de uma ótica humanizada, não flerta com a parcialidade ou com falta de ética. Humanidade, diga-se, não é bondade, mas se relaciona com a ato de afetar e ser afetado pelo contato próximo com o outro, é saber que as suas decisões terão consequências práticas na vida do réu, das partes, das pessoas.

Assim, não se entende, ao menos nesse breve estudo, a conduta ativista por parte do magistrado como sendo, em essência, anti-jurídica ou anti-democrática. Essa é sim perigosa, e caminha paralelamente à parcialidade e, por vezes, ao partidarismo político. Porém, credita-se tais falhas a um estado de moral individual pouco envolto em uma ética tão necessária e inerente à profissão de magistrado. A postura ativista deve vir imbuída de, com o perdão pelo altruísmo, nobreza e dignidade. Portanto, a importância de um comportamento pautado pela ética deve ser repetidamente ensinada desde os cursos de graduação. A cultura do gift-gift ou do toma lá da cá deve ser desencorajada e, se possível, varrida da realidade jurídica brasileira, porém, tal ideal ainda parece demasiado abstrato.

Socialmente, pode-se dizer que o cidadão brasileiro carrega marcas e cicatrizes difíceis de serem apagadas, vieses culturais relacionados ao jeitinho brasileiro predominam. Porém, muito já foi feito no sentido de dar um basta para a corrupção da classe política, sendo ao que parece, chegada uma era da intolerância em relação aos malfeitos e desmandos políticos. O fim de todo um tempo de coronelismo e de ganância institucional. De toda sorte, tendo em vista tudo o que se passou nos últimos anos, as manifestações, a mudança de clima político e institucional, a intensificação dos debates entre a esquerda e a direita, a criminalização da política e, em virtude dessa última, a crescente judicialização, ainda assim, sente-se que o país saiu ganhando.

\section{Referências}

BARBOZA, E.M.Q.; KOZICKI, K. Judicialização da política e controle judicial de políticas públicas. Rev. Direito $G V$, v.8, n.1, p.59-85, 2012.

BARROSO, L.R. "Aqui, lá e em todo lugar": a dignidade humana no direito contemporâneo e no discurso transnacional (Here, There, and Everywhere: Human Dignity in Contemporary Law and in the Transnational Discourse). Boston College Int. Comp.ve Law Rev., v.35, n.2, p.331-394, 2012.

BARROSO, L.R. Judicialização, ativismo judicial e legitimidade democrática. RDE. Rev. Direito do Estado, v.13, p.71-91, 2009.

BARROSO, L.R. Pesquisas com células-tronco embrionárias e interrupção da gestação de fetos anencefálicos: vida, dignidade e direito de escolha. In: SARMENTO, D.; SARLET, I.W. (Coord.). Direitos fundamentais no Supremo Tribunal Federal: balanço e crítica. Rio de Janeiro: Lumen Juris, 2011.

BARROSO, L.R. Trinta anos da Constituição: a República que ainda não foi. Rev. Eletr. PGE RJ, v.1, p.1-19, 2018. 
BARROSO, L.R.; OSÓRIO, A. Democracia, crise política e jurisdição constitucional: o protagonismo da Suprema Corte do Brasil. Rev. Eletr. PGE RJ, v1, n1, 2018.

BARTOLOMEI J.R.; REZENDE, L.F. Judicialização da saúde e internações Compulsórias de jovens usuários de Drogas: um estudo em Espírito Santo do Pinhal/SP. Rev. Direito Sanit., 2017.

BUCCI, E. A forma bruta dos protestos: das manifestações de 2013 à queda de Dilma Roussef em 2016. São Paulo: Companhia das Letras, 2016.

CHAIA, V. Democracia e escândalos políticos. São Paulo Perspec., v.15, n.4, p.62-75, 2001.

CIOCCARI, D. Operação Lava Jato: escândalo, agendamento e enquadramento. Rev. Alterjor, v.12, n.2, p.58-78, 2015.

DWORKIN, R. Justice for hedgehogs. Cambridge: Harvard University Press, 2011.

ENGELMANN, F. Da "Crítica do Direito" ao "combate à corrupção": deslocamentos do ativismo político-judicial. Contemporânea, v.7, n.2, p.297-312, 2017.

FEREJOHN, J.; PASQUALINO, P. 'Rule of Democracy and Rule of Law. In: PRZEWORSKI, A.; MARAVALL, J.M. democracy and the rule of law. Cambridge University Press, 2003. p.242260.

FERREIRA FILHO, M. G. Corrupção e Democracia. Rev. Dir. Adm., v.226, p.213-218, 2001.

GADAMER, H.-G. Verdade e método. Petrópolis: Vozes, 1997.

LEAL, M.C.H.; ALVES, F.D.A. Judicialização da Política e do Direito: um fenômeno decorrente de múltiplas causas, sob diferentes abordagens. In: SEMINÁRIO INTERNACIONAL DE DEMANDAS SOCIAIS E POLÍTICAS PÚBLICAS NA SOCIEDADE CONTEMPORÂNEA. Santa Cruz do Sul: EdUNISC, 2014.

LEVITSKY, S.; ZIBLATT, D. Como as democracias morrem. Rio de Janeiro:. Zahar, 2018.

MACIEL, D.A.; KOERNER, A. Sentidos da judicialização da política: duas análises. Lua Nova n.57, p.113-133, 2002.

McCOMBS, M..; SHAW, D.L. A função do agendamento dos media, 1972 In: TRAQUINA, N. O poder do jornalismo: análise e textos da teoria do agendamento. Coimbra: Minerva, 2000.

MICHENER, G.; PEREIRA, C.. A Great Leap Forward for
Democracy and the Rule of Law? Brazil's Mensalão Trial'. J. Latin Am. Studies, v.48, n.3, p.477-507, 2016

MEDEIROS, C.R.O.; SILVEIRA, R.A. A Petrobrás nas teias da corrupção: mecanismos discursivos da mídia brasileira na cobertura da Operação Lava Jato. Rev. Contab. Organiz., v.11, n.31, p.12-20, 2017.

MELLO, P.P. Nos bastidores do STF. Rio de Janeiro: Forense, 2015.

MELLO, P.P. Trinta anos, uma constituição, Três Supremos: autorrestrição, expansão e ambivalência no exercício da jurisdição. In: PAULINO, L. A. Constituição, direitos politicos e jurisdição. Rio de Janeiro: Lumen, 2018.

MELO, M.A. Crítica à cobertura midiática da Operação LavaJato. Rev. Bras. Ciênc. Criminais, 2016.

MIGUEL, L.F.; COUTINHO, A.A. A crise e suas fronteiras: oito meses de 'mensalão' nos editoriais de jornais. Opinião Pública, v.13, n.1, 2007.

SANTOS, F. Do protesto ao plebiscito: uma avaliação crítica da atual conjuntura brasileira. Novos Estudos, n. 96, p.15-25, 2013

SHAPIRO, I, The Rule of Law. Nomos XXXVI. New York University Press, 1994.

SILVA, T. Acontecimento: evocando sentidos, provocando ações: uma análise do "Mensalão". Intexto, n 30, p.72-92, 2014.

STERN, A.L.S. O Caso Marbury Versus Madison: o nascimento do judicial review as a political artifice. Rev. Direito Liberdade, v.18, n.3, p.193-212, 2016.

RIBEIRO, A.G.; MARTINS, V.F. Investigação no Brasil: a opinião dos auditores independentes nos relatórios das empresas envolvidas na "Operação Lava Jato". AJOICA, n.15, 2016

TASSINARI, C. Jurisdição e Ativismo Judicial. Porto Alegre: Livr. Do Advogado, 2013.

TATE, C.N.; VALLINDER, T. The Global Expansion of Judicial Power. Nova York: New York University Press, 1995.

TEIXEIRA, A.V. Ativismo judicial: nos limites entre racionalidade jurídica e decisão política. Rev. Direito $G V$, v. 8, n.1, p.37-57, 2012 .

VERBICARO, L.P. Um estudo sobre as condições facilitadoras da judicialização da política no Brasil. Rev. Direito GV, n. 4, 2008. 
Uma Análise Sobre a Expansão do Poder Judicial no Brasil: Construindo Sentidos sobre Democracia e Ativismo Judicial 
DELUQUE JUNIOR, R. 
Uma Análise Sobre a Expansão do Poder Judicial no Brasil: Construindo Sentidos sobre Democracia e Ativismo Judicial 